Rand, Jane ORCID:

https://orcid.org/0000-0002-2314-6761 (2015) Dimensions of knowing: a conceptual alternative to an unhelpful polarity between knowledge and skill. Research in Post-Compulsory Education, 20 (2). pp. 140-158.

Downloaded from: http://ray.yorksj.ac.uk/id/eprint/659/

The version presented here may differ from the published version or version of record. If you intend to cite from the work you are advised to consult the publisher's version: http://www.tandfonline.com/doi/abs/10.1080/13596748.2015.1030245

Research at York St John (RaY) is an institutional repository. It supports the principles of open access by making the research outputs of the University available in digital form. Copyright of the items stored in RaY reside with the authors and/or other copyright owners. Users may access full text items free of charge, and may download a copy for private study or non-commercial research. For further reuse terms, see licence terms governing individual outputs. Institutional Repository Policy Statement

\title{
RaY
}

Research at the University of York St John

For more information please contact RaY at ray@yorksj.ac.uk 
This is an author's pre-print version of an article published in Rand, J. (2015) Dimensions of knowing: a conceptual alternative to an unhelpful polarity between knowledge and skill. Research in Post-Compulsory Education, 20(2), 140-158. DOI:

10.1080/13596748.2015.1030245

To link to this article: http://dx.doi.org/10.1080/13596748.2015.1030245 


\section{Dimensions of knowing: a conceptual alternative to an unhelpful polarity between knowledge and skill.}

This paper reports research which explored an 'experienced problem' (Coghlan and Pedler 2006, 129) of an unhelpful polarity between knowledge and skill in English post-compulsory education and training (PCET). I developed a model of knowing designed to promote an alternative conceptualisation; the research set out to operationalise Dimensions of knowing in a real context and explore its potential. The research participants were PCET teacher-trainees. I chose a conflated research approach of constructivist grounded theory methodology supported by the principles of action learning. This approach both enabled practitioners to engage collaboratively and reflexively with the model, and also allowed me to develop an objectified explanatory framework of their engagement. The implications of this research are that Dimensions of knowing could support an alternative to a binary epistemology, commonly associated with the PCET curriculum. Used as a conceptual 'tool' within PCET teacher education, Dimensions of knowing has the potential to lighten a dualist 'experiential residue': Tomlinson's $(1999,535)$ description of the 'default options' of student teachers which results form their own experience of schooling.

Keywords: academic:vocational divide; PCET ITE; action learning; constructivist grounded theory; dimensions of knowing. 


\section{Introduction}

This paper reports research which responds to an argument (developed in part one of a professional doctorate) that there is an unhelpful polarity between knowledge and skills within the dominant discourse of English post-compulsory education and training (PCET). Such a binary view risks the 'separation and superiority of mental knowledge over manual skills' (Ainley 2000, 6) and fosters an academic:vocational divide.

The contextual underpinning to this research was three-fold: policy, practice and discourse. Firstly, The Further Education Teachers' Qualifications (England) Regulations 2007 established the reform of English (post-compulsory) Initial Teacher Education in law (see Endnote). It mandated the vision in Equipping our Teachers for the Future (DfES 2004, 5) that teachers in the sector should be dual-professionals, trained and qualified in their subject area and (at graduate-level) in 'the skills of teaching their subject'.

My research interests were underpinned by the practical contextualisation. My experience, as a teacher-educator in an English Further Education College, was that PCET teacher trainees often perceive their professional identities as differentiated by the academic or vocational curricula on which they teach. To paraphrase a student's comment: "I can't do this [essay], I'm a 'plumber' ... not an academic". Tomlinson $(1999,535)$ describes this as 'experiential residue' - the 'default options' of student teachers which results from their own experience of schooling.

Without problematisation of the dominant discourse of an academic:vocational divide within the sector, there is a risk that trainee teachers both intrinsically accept, and extrinsically promote a binary view. This conflicts with the expectations of 
contemporary teaching environments, which demand the integration of the practical and theoretical, of the social and natural, of subject knowledge and educational knowledge (Dehmel 2006; Ainley 2000; Bathmaker 1999). This was my 'experienced problem’ (Coghlan and Pedler 2006, 129) and it is because my research was both 'from' and 'for' practice that I chose an action-oriented framework (Pedler 2001, 298) through which to explore it.

I developed a proposition that skill 'rather than existing separate to knowledge is, in fact, evidence or application of knowledge, be it practical (applied) or theoretical (pure)' (Rand 2009, 6). In opposition to a binary view, I suggested that knowledge of and skills in should be considered as interconnected, dynamic, mutually sustaining and developmental. As a result of my exploration I developed a model of knowing designed to promote an alternative to a binary conceptualisation. The model has two key features:

(1) it is based on three dimensions of generality (width), complexity (depth) and materiality;

(2) the interconnected, dynamic and mutually sustaining relationship between these dimensions is conceptualised through a portrait of knowing, occupying an 'irregular space, reflective of an individual agent's unique set of experiences at any given time (Rand 2009, 22).

Materiality, the dimension which differentiates my conceptualisation from the work of others (Entwistle 1995, 2000, 2004, 2009; Entwistle and Ramsden 1983; Entwistle and Marton 1994), relates to agents' process/es of drawing on the width (generality) and depth (complexity) of their individually-nuanced knowledge. 
The research was practice- and practitioner-centred. It focussed on the operationalisation of my conceptual model within a real context, with PCET practitioners engaged either in initial teacher education (ITE) or continuing professional development (CPD) activity.

In contrast to a more traditional research approach which starts with a review of a topic and is aimed at finding a gap in the literature; this research started from my 'experienced problem' (Coghlan and Pedler 2006, 129). It re-framed the problem as a gap in the literature and positioned my research within a body of knowledge. My goal was to learn about how training PCET practitioners think about knowing, and my model was used as a stimulus to support this. I needed a research approach which helped me to better understand the complexity of my experienced problem, which ensured that the target(s) of my inquiry remained appropriately contextualised, and which enabled me to explain the interrelationship between conditions, actions and consequences of practice. I therefore chose to conflate a constructivist grounded theory methodology with a datageneration strategy informed by action learning. Action learning is 'a continuous process of learning and reflection that happens with the support of a group or 'set' of colleagues, working on real issues ...[and] which recognizes set members' social context...' (McGill and Brockbank 2004, 11). This choice, to conflate two previously uncombined approaches is justified, and problematised, elsewhere (Rand, 2013).

The challenge for a professional doctoral student who adopts an action-oriented approach is to demonstrate the capacity 'to make a significant contribution to knowledge...[and] ... a significant original contribution to practice' (Bourner and Simpson 2005, 144). This is achieved through testing 'knowledge from an inner 
source' (introspection) against other knowledge sources, of reason (deduction or logic), received knowledge and empiricism (Bourner and Simpson 2005, 134-5). This links personal knowledge to the "wider system in which the researcher and the problem are located' (Coghlan and Pedler 2006) and therefore to the advancement of knowledge. Coghlan and Pedler $(2006,136-7)$ outline three criteria for evaluating the quality of action learning research: evidence of real problems being addressed, action being taken and learning taking place. These principles have been adopted as a broad structure for this article, with an additional focus on analytical sense-making, to report the outcomes from my methodological choice of constructivist grounded theory.

\section{Evidence of real problems being addressed}

The OECD (1996) defined teaching as one of many knowledge-based jobs, located within a knowledge economy, that is one based on both learning codified information and the competencies to use it. Such an economy demands a theoretical [re]integration of knowledge and skills (Ainley 2000). Knowledge-based jobs are predicated on change (OECD 1996) and there is therefore an argument that the capacity to conceptualise knowing - a changeable, agent-specific state - is a threshold requirement for effective teaching. This makes knowing an essential concept within an ITE curriculum. I have conceptualised knowing as:

understanding, on a continuum between the concrete (applied) and the abstract (pure), which can be demonstrated in terms of an individual's power or capacity to engage with and/or employ (that) knowledge - referred to as skill. (Rand 2009, 5)

My model originated from a critical review of notions of knowledge and knowing, these 
ranged from dichotomous views to those which accommodated wider perspectives. Binary distinctions of codified and tacit knowledge assume objectivity: 'Codified knowledge might be considered as the material to be transformed, and tacit knowledge, particularly know-how, as the tool for handling this material' (OECD 1996, 13). This fails to account for underpinning complexities; the influence of variables, and the implicit role of agency deserve consideration. Albino, Garavelli, and Schiuma (2001) propose a five point metric to codify knowledge states: intuitive, tacit, qualitative, quantitative and scientific. Designed in response to an issue of organisational development, they argue that it is possible to evaluate learning requirements more accurately by identifying the predominant knowledge state and focussing the skills (which they refer to as ability components) required to develop it. They argue that knowledge and ability coincide: ' ...it is always possible to associate knowledge with an ability and then a task to be performed, that can result in a material... or immaterial asset' (Albino, Garavelli, and Schiuma 200, 415). Their proposition recognises the interdependence of knowledge and skills, and the capacity of the knower to exploit different categories of knowledge. Their proposition provides a much thicker description of knowledge states than a dichotomous model allows and, whilst the role of agency is not well accounted for in their work, I argue that their metric lends itself generally to cognitive systems. Cognitive systems can be human or organisational.

Within human cognitive systems, knowledge is considered a correlational structure. Ancori, Bureth, and Cohendet $(2000,265)$ argue that 'knowledge is closely dependent on the cognitive abilities of the actors who hold it... [it] cannot be considered separately from the [agent-specific] communication processes through which it is exchanged. They describe knowledge topologically, with width and depth corresponding to degrees of generality and complexity. They argue that agents' ability 
to adjust the width and depth is knowledge-management. This (knowledgemanagement) is similarly described by Claxton $(2006,4-5)$ as 'epistemic identity' individual tolerances which expand or contract agents' learning (knowing) capacity. Others share the view that knowledge is correlational. Subject matter and the process(es) of learning can be considered as warp and weft in an 'infusion approach' (Claxton 2006, 11), where knowledge and skill are reconceptualised:

There is indeed no skill in the exercise of which knowledge does not play a part and, likewise, there is no knowledge that does not rely upon skill to apply or express it. Fundamentally, knowledge and skill cannot be distinguished because mind and body cannot. (Ainley 2000, 6)

My own conceptualisation of knowing conflated the work of Ainley (2000); Albino, Garavelli, and Schiuma (2001); Ancori, Bureth, and Cohendet (2000); and Claxton (2000) and led to a model predicated on two key elements. The first of these is the three dimensions of generality, complexity and materiality. Generality (width) and complexity (depth) are, of course, central to others' critical accounts of knowledge and skills; notably the work of Noel Entwistle. What differentiates my conceptualisation is the third dimension of materiality. Materiality relates to the constituent elements which show (to the eye or the mind) the width and depth of an agent's knowing.

The second key element is a portrait of knowing. A portrait is a description, picture or representation. An individual's portrait of knowing represents the relationships, at any given time, between the three dimensions. It occupies an irregular space. It accommodates the dynamic, mutually sustaining and developmental connection between the dimensions. It eschews the notion of single point of intersection. 
In my research, I argued that the complexity of 'knowing' can be more easily understood through conceptual modelling. The research set out to determine the potential for my model to contribute successfully to this within a PCET environment. In practice, the purpose of the model was not directive but, as Illeris (2006: 155) suggests, facilitative: 'a kind of map illustrating a certain view of a field and providing the reader with an overview'.

In order to share this 'map' I chose an easily recognisable three-dimensional shape (a cube), with a transparent format to encourage conceptualisation of a portrait of knowing within it. In an early version of Dimensions of knowing (Figure 1) I chose the (arguably naïve) terms high and low to indicate the boundaries of generality and complexity. I adopted the terms physical and mental to indicate the boundaries of materiality, from the authors whose work had led me to propose it (Albino, Garavelli, and Schiuma 2001; Ainley 2000; OECD 1996).

Figure 1. Dimensions of knowing \#1 (Rand 2009, 22)

An example of the concept of a portrait of knowing was articulated in my original work (reproduced below). No attempt was made to depict a portrait within the model; however participants subsequently adopted an analogy to the lava in a lava lamp. 
An individual studying at doctoral level within a Social Science discipline would typically have low/medium generality, high complexity, and a tendency for mental materiality. The portrait for an individual studying at undergraduate level in the same discipline would typically have a lower complexity.

The portrait of someone studying a subject typified with physical materiality may tend towards increased generality, for example through drawing on the laws of engineering; however, it will not necessarily have low complexity - consider the (simplified) difference between building a wall and constructing a house. (Rand 2009, 22)

My research was, of course, situated within an established field of enquiry. However, an action-oriented methodological approach based on theory-generation demanded a non-traditional approach to engaging with the extant literature. In action learning research, engaging with literature and sense-making follows reflection on, and reframing of, an experienced problem (Coghlan and Pedler 2006). Similarly, constructivist grounded theory encourages 'theoretical agnosticism' - a delayed literature review, woven in to the research discussion, geared towards encouraging articulation of the researcher's ideas (Henwood and Pidgeon 2003 as cited in Charmaz, $2006,165)$. However an overview of the field of enquiry was necessary for contextualisation; the work of Noel Entwistle, a key contributor to contemporary research about knowledge and understanding in higher education, provided that context.

\section{Connecting to the work of Noel Entwistle}

Collaborating with Paul Ramsden in 1983, Entwistle explored the processes associated with students organising their thoughts. Designed to conceptually and empirically expand on earlier work on approaches to study, which tended towards dualistic 
conceptualisations, Entwistle and Ramsden (1983) championed a pluralistic view of intellectual development. They developed a proposition for the combination and interrelation of knowledge and (technical) skills. Drawing on work published in the 1970s (notably of Säljö, Marton, Svensson, and Pask), Entwistle and Ramsden (1983) proposed that approaches to learning were typically understood as the opposition between an intention to understand (deep, holistic, comprehension learning) and an intention to memorise (surface, atomistic, operation learning).

In 1994, working in partnership with Ference Marton, Entwistle focussed on undergraduate students' experience of developing academic understanding. Five forms of understanding (distinctive individual strategies) were identified. The key significance in this research related to Entwistle and Marton's (1994, 163-4) differentiation of three characteristics within the categories, based on breadth, depth and structure:

Breadth of understanding described the range and amount of information which students sought to integrate during the revision process. Some students relied to a substantial extent on their lecture notes alone, whereas others, to varying degrees in their revision, brought together notes on additional reading.

Depth of understanding was seen in terms of the extent to which students invested effort and commitment in seeking understanding for themselves. This process involved developing a set of interconnections between aspects of the material studied which might be expected to increase the overall coherence of the learning outcome.

Finally, students differed not only in the extent to which they managed to interrelate the component ideas and concepts but also in the type of structure which they used in that organisation. Some students were content to rely on the logical structure and arrangement provided within their lecture courses. Thus, the coherence reflected in such students' answers to exam questions had not been independently developed: it was derived mainly from the lecturer. In contrast, and 
in rather different ways, other students sought to reorganise their notes so as to impose their own organising framework on the material.

Entwistle and Marton (1994, 166, 169) hypothesised that agents' perceptions of their understandings were experienced as an 'entity with form and structure', which they described as a knowledge object - a multi-dimensional and evolving concept typified by tight integration of related knowledge, but the 'defining features' of which 'emerge fully only where broad, deep and personally structured understandings have been established'.

Knowledge objects therefore are products of intentions and processes. Their nature depends on the range of information incorporated (breadth), the depth of engagement, and the framework/s within which it is delivered (structure). It is the dimension of structure which underpinned the distinctions between the five forms of understanding:

(1) Absorbing facts, details and procedures related to exams without consideration of structure.

(2) Accepting and using only the knowledge and logical structures provided in the lecture notes.

(3) Relying mainly on notes to develop summary structures solely to control exam answers.

(4) Developing structures from strategic reading to represent personal understanding, but also to control exam answers.

(5) Developing structures from wide reading which relate personal understanding to the nature of the discipline. (Entwistle and Marton 1994, 163) 
There are immediately obvious similarities between Entwistle (and colleagues') work, and my own model. 'Knowledge objects' and 'portraits of knowing' draw similarly on three dimensions. Entwistle and Marton's (1994) dimension of 'breadth of understanding' and my own dimension of width (generality) appear mainly consistent. Similarly, 'depth of understanding' and my dimension of depth (complexity) both relate to extent of engagement. The key difference relates to the third dimension. In my model, width and depth are dimensions of knowledge of, and materiality relates to the constituent elements which show (to the eye or the mind) the width and depth of an agent's knowledge (skills in). For Entwistle and Marton the third dimension, structure, relates to the extent to which agents' reconstruction of knowledge is individualised.

This is an important distinction in two ways. Primarily the third dimensions serve different purposes in each model. Secondly, Entwistle and Marton's (1994) study is geared towards students' perceptions and experience of learning. My research took advantage of an opportunity to work with participants occupying a dual-role of teacher and student. It foregrounds social constructivism - an interest in groups' perceptions (and their determinants), and their shared contextual meaning-making. This presented two opportunities for research originality: an exploration of the potential of my own (tri-dimensional) model of knowing, and consideration of the nature of knowing for those occupying a dual teacher/student role.

\section{Research frame}

In accordance with BERA guidelines $(2004,5)$, the research was conducted within an ethic of respect for people, knowledge, democratic values, quality of educational 
research and academic freedom. Participants (derived from an opportunistic sampling strategy) were active agents within the research, and participation was on the basis of voluntary, written, informed consent. I had an existing professional relationship with all participants, as a tutor on both the in-service Diploma in Teaching in the Lifelong Learning Sector (DTLLS) and the BA (Hons) PCET programme in the research setting a rural, general Further Education College in England.

Two research questions were developed for the study, the first of which is the focus of this article:

(1) How do training PCET practitioners engage with a conceptual model of knowing based on three dimensions of width, depth and materiality?

(2) What does this tell us about the potential for this model to contribute to the conceptualisation and development of the post-compulsory curriculum?

In common with grounded theory approaches, data collection and analysis was simultaneous. Analytic codes were constructed from the data, which in turn were subject to the constant comparison method. The medium of memo-writing was used to 'elaborate categories, specify properties, define relationships and identify gaps' (Charmaz 2006, 5-6). This style, typified by interspersed reporting and analysis, supported the evolution of the data (Marshall and Rossman 2006). It resulted in a substantive grounded theory framework - an explanatory theoretical framework of a delimited and particularistic research context (Figure 4). 


\section{Evidence of action being taken}

I had the opportunity to work with 50 training PCET practitioners initially through two rounds of reflective workshops informed by action learning. Both workshop rounds were facilitated with three independent student cohorts (two DTLLS and one BA PCET).

In Workshops A I presented my model to participants and introduced the concept of critical colleagueship (Lord 1994) - collaborative discussion geared towards 'gaining a deeper understanding and development of practice' (Plauborg 2009, 31). These workshops concluded with a formal activity based on an action learning set. Participants were invited to identify a current and real (professional) problem for collaborative, reflective discussion within the set and, where appropriate, my model was used as a stimulus.

Data generated from the first round of workshops was captured through a postit $^{\mathrm{TM}}$ note activity and the use of summative artefacts (feedback sheets completed by participants). These data comprised characteristics of participants' own portraits of knowing, and examples of how participants interpreted my model.

Initial coding of the data was geared towards 'labelling' actions and processes (Moghaddam 2006). Each label was supported by segments of data, which LaRossa (2005) calls indicators. A verification process of constant comparison of indicators within and between labels resulted in a process of confirmation, aggregation or separation of each label; these became initial conceptual codes. This concept-indicator process (LaRossa 2005), along with memoing and diagramming (common in grounded theory approaches) was used to identify four organising principles in the data: 
- analysing

- planning

- reflecting

- diagnosing

I found that training practitioners were capable of conceptualising knowledge of and skills in as interconnected, dynamic and mutually sustaining. I also found that knowledge of the model without skills in its interpretation limited practitioners' early engagement. I initially viewed this as participants misinterpreting my model. After discussion with my supervisor, as critical friend, I re-framed this as participants reinterpreting my model through a binary lens. However, a contributory factor to this reinterpretation was the language I had adopted to define the boundaries of each dimension in my model (Figure 1). The data which emerged from the first round of workshops suggested three points of departure (Kathy Charmaz' [2006] term for the choices which underpin emergent data collection approaches within a constructivist grounded theory):

(1) Could alternative language to delimit the dimensions within the model open up how practitioners interpret it, such that participants engage with its implicit epistemological assumptions?

(2) Would developed knowledge of the model promote more consistent engagement?

(3) What capacity do the organising principles of analysing, planning, reflecting, and diagnosing have to become formal categories within the grounded theory? 
Workshops B comprised two, practitioner-led, activities: a review of the language used to delimit the model's dimensions; and an exploration of the potential of my model in a real context, through reflective discussion based on the principles of an action learning set. A second summative artefact sheet was used to capture both participants' preferred language for the model's dimensions and also examples of how practitioners would make use individually of the model.

In exploring the first point of departure a consensus view on suitable language for the complexity and generality dimensions was quickly reached; the original language of 'high' and 'low' was not chosen by any participants. The materiality dimension was considered less straightforward. The original language of 'physical' and 'mental' was chosen by some participants. In one workshop these terms dominated the choice; however participants chose deliberately to invert the axis labels, indicating physical at the top of the model and mental at the bottom. My research notes revealed the rationale behind this decision:

...participants generally reported that they still felt that placing mental "above" physical...would give the impression that mental skills were "better" than physical ones. (Extract from fieldnotes: Workshop B2)

In total, eight alternative terms to delimit the materiality axis were discussed: abstract, applied, conceptual, concrete, mental, physical, practical and pure. Across all three workshops, the outcome from the activity demonstrated a preference for terms related to physicality at the top of the dimension. I had anticipated that participants may replicate 
Kolb's (1984) experiential learning cycle - a commonly used model within PCET ITE.

However, the sense I got from the plenary discussions was not that participants' decisions related to their knowledge of Kolb's cycle (common practice of which depicts concrete experience at the ' 12 o'clock' position, in opposition to abstract conceptualisation); rather it was a deliberate attempt to promote 'physical' over 'mental'.

However, opportunities within the workshops for facilitated critical reflection were taken up by participants and this critical colleagueship supported the exploration, and development, of practitioners' unexamined views (Mezirow 1981). Notably, in each workshop varying reference was made to placing a learner inside the box. Whilst this is counter to my ideology of a portrait of knowing, an extract from a research memo (below) illustrates practitioners' development of a more consistent (re-)interpretation of the model, after reflective discussion:

[In Workshop B1] Wilma suggested that abstract/conceptual suggested thinking, and concrete/applied suggested "grounded" [participant's terms]. She revealed that she had an idea of a person inside the 3D model, with a head at the top of the materiality dimension and feet at the bottom; arms \& legs could be moved around - to show movement in the other dimensions. The rest of the group liked this idea, and therefore agreed that if abstract was chosen as the axis label, then it should be at the "top" of the materiality dimension...In Workshop B2 there had also been discussion about "placing a learner inside the box". In contrast in B3, where there was an 8:5 split for terms related to physical materiality at the top of the dimension, one participant (Chrispy) shared her justification for placing mental above practical; because she relates head above hands ...Another participant (Siena) who had previously expressed a preference to swap the materiality \& generality dimensions ... because she felt very strongly about the visual 
representation of high and low on the materiality dimension, commented that this "immediately removes the low/high concept"

Siena's reaction supports my belief that training practitioners perceive physical and mental materiality as discrete, and associate differentiated values to each. I suggest that these are 'unexamined views' (Mezirow 1981), based on cultural assumption and the custom and practice that these practitioners are familiar with. Although they are fighting against any interpretation of mental being higher than physical, practitioners perpetuate the divide through responses which promote reversing the relationship, and maintaining the binary rather than considering the terms as extremes of a continuum and recognising their interrelationship/s. (Extract from memo 007)

Results from the activity suggested there was value in amending the language I used within my model to delimit the three dimensions (Figure 2).

Figure 2. Dimensions of knowing \#3 (Rand, 2011)

\section{Re-visiting the points of departure and engaging with the data.}

In the second round of workshops, (re-)interpretation of my model was better connected to its implicit epistemological assumptions; I surmised therefore that the use of alternative language did open it up to practitioners (point of departure one). Furthermore, co-creation of the new dimension delimiters also provided an extended opportunity for practitioners to develop their knowledge of the model. Whilst this is not an inferential relationship, the complementary nature of points of departure one and two should be acknowledged. Forty-five individual examples of how practitioners would make use of the model were recorded in the summative artefacts; all were related to 
formalising 'knowing' in some way. I felt confident therefore that this extended interaction with my model successfully developed participants' knowledge of it and it did therefore promote more consistent engagement (point of departure two).

The third point of departure focussed on the four organising principles which surfaced after early abstraction of the first dataset. The process of constant comparison illuminated that planning, reflecting and diagnosing were in fact embedded within the analytic processes revealed within the data set. As a result, it was determined that these three initial categories had limited capacity to become formal categories. Analysing was, however, significant as an organising principle for two reasons: it dominated the data segments which related to participants' engagement with my model, and it withstood de-contextualisation (Bowen 2006; Charmaz 2006; van den Hoonaard 1997).

\section{Analytic sense-making}

Abstraction of analysing was achieved by re-viewing the entire data set (generated across all six workshops); 132 discrete data segments were identified. The data were sorted by considering what behaviours (or intended behaviours) were indicated by the data segments; this enabled me to see the differentiated purposes to which practitioners directed their analytical processes. Broadly these were geared towards:

- identifying a condition

- effecting action; or

- coming to a judgement 
Through the processes of memoing, each of these was considered in critical depth; Table 1 summarises how the language of the research developed. The three categories of analysis demonstrated by practitioners were indicative, performative and summative.

Table 1. Developing a language for my research

Considering the data in terms of behaviours enabled better engagement with the implicit, and identification of data properties which were capable of withstanding decontextualisation. The scope (measurable extent) of each category was accounted for through examining the focus of practitioners' analysis. In this substantive, small-scale study each category's scope was similar, broadly spanning self, others and professional situations. Examples of the three analytic behaviours are included in Table 2.

Table 2. Examples of the three analytic processes.

Since these three categories both adequately withstood abstraction from their original context, and collectively accounted for all of the data segments they were considered capable of contributing effectively to the theorisation of practitioners' engagement with my model. As a result, the process of constructing a substantive grounded theory framework could move forward to the analytical probing of theoretical sampling in a third round of workshops.

Theoretical sampling is concerned with analytical sense-making and theory generation. It is the process of collecting more data to refine, strengthen and elaborate categories; to discover variations and define gaps. It is specific and systematic, and concerned with examining the researcher's ideas about the data through further empirical inquiry. It is the process through which induction meets deduction in 
interpretive research. Charmaz $(2006,103)$ calls this abductive reasoning - testing empirically-based theoretical conjectures by re-entering the research field, checking hunches and exploring relationships between categories (Charmaz 2006, 102,104). In GTM, memoing and diagramming facilitate the exploration of relationship/s between categories, their properties and the conditions under which they are linked. Theoretical sampling is therefore concerned with how the components of a grounded theory framework relate.

Nickerson's (1995) work on representation supported the process of theorisation. It enabled a differentiation between 'naïve' and 'dynamic' representation of knowing within the dataset. In turn this led to a productive exploration of the properties of the three abstracted categories, and resulted in the explanatory terms: symbolisation and envisionment of knowing. Symbolisation was typically indicated by (naïve) measurement or quantification. Envisionment, based on Nickerson's definition: '...that permits one to run a qualitative simulation in the mind's eye $(1995,226)$, was indicated by (dynamic) data segments with greater density:

Thinking about my learners needing to have the mental knowledge to carry out the practical skills, they would need to have a knowledge of (generality) but this would be built on and move further toward the broad as the learners were taught more. Their depth (complexity) would also be towards the shallow at the beginning of their course, moving towards deep as they learned and understood more about their course. (I(B)58)

These properties were tested by revisiting the field and generating a third data set. This iterative and evolutionary approach to the data enabled sense-making of practitioners' 
engagement with the model. It represents the substantive underpinning to the theoretical framework (Figure 4), in which symbolisation accounted for naïve, explicit, absolute and quantitative expressions of knowing, and envisionment accounted for dynamic, implicit, thematic, and qualitative explanations of knowing (Marton and Säljö 2005; Nickerson 1995; Säljö 1979).

As a result of these iterative processes, a tentative theoretical synthesis (van den Hoonaard 1997) could be determined, that training PCET practitioners used the model to support:

Indicative, performative, or summative analysis of themselves, others or professional situations, geared towards accounting for existing [portrait/s of] knowing or concretising anticipated [portrait/s of] knowing through a process of symbolisation or envisionment.

\section{The motion in the data}

The construction of abstract understandings, or theorising as practice (Charmaz 2006) required the relationship/s between the three categories of analytic behaviour and their properties of symbolisation and envisionment to be explored. This was achieved through determining what enabled symbolisation or envisionment.

In practice this meant disregarding the literal, avoiding conjecture about participants' (own) meanings within the data segments, 'plumb[ing] the depth... while expanding the reach' and grappling with both the overt and covert to get theoretical 'level and density' (Charmaz 2006, 123-4). This process of re-viewing the data, and theorising hinged on memoing and mapping (diagraming); these processes expedited the analytical distance needed to build a sufficiently robust interpretive framework and allowed me to appreciate the 'motion' in the data (Lempert 2007, 252). 
Literal routes through the data suggested a fuzzy margin between indicative and performative analysis, and a broadly even likelihood of symbolisation or envisionment as an outcome of the analysis of others. Exploring the covert alongside the overt, however, allowed me to see the dominant motion in the data was indicative analysis of others, resulting in symbolisation. Four implicit processes were also interpreted:

- orientation - determining position;

- perception - becoming aware of;

- intention (to act) - having in mind to do/achieve; and

- evaluation - determining 'worth' (typically a comparative version of orientation, which included a judgement of the value of the compared position or knowledge state).

These four processes were underpinned by practitioners' implicit questions (Table 1). They constitute a typology of the motion in the data. This typological approach is helpful because it connects practitioners' implicit questions, the three analytical categories, and the outcomes of symbolisation and envisionment:

- Orientation is geared towards positioning or locating - typically in response to the implicit questions of where, and what?

- Perception is geared towards developing awareness. It often follows orientation, and responds to the combined implicit question of where, and why? 
- Intention is concerned with directing professional attention. It is solely connected to performative analysis and often develops from or responds to perception. It is connected to the combined implicit question of where to, and how?

- Evaluation is about determining worth. It is typically a comparative measure, and responds to implicit questions such as where now, and how much?

- Orientation and evaluation are principally quantitative and expressive. They are limited to analysis which is indicative or summative. They bring about symbolisation.

- Intention is unique to performative analysis. As a discrete process, it can bring about either symbolisation or, the more explanatory and qualitative outcome of envisionment. However, when combined with perception, the result is more typically envisionment.

- Perception is evident across each of the analytic categories. Discretely, it can bring about either symbolisation or envisionment, but combination with either orientation or intention typically results in envisionment.

\section{Towards a substantive grounded theory}

In a traditional grounded theory methodology the concept of a core category, one with ‘explanatory and predictive power' (Charmaz 2006, 139), it is considered indisputably fundamental (Holton 2007). However, for the constructivist grounded theorist, the concern is differently focussed on 'carrying capacity'. That is, the extent to which a category can carry forward the analysis (personal communication between Clarke and Charmaz as cited in Charmaz 2006, 139). Each of the categories within my framework 
has 'reach and power, within and beyond' the environment in which they were situated (Charmaz 2006, 128). Notably, indicative analysis 'hold[s] more significance, account[s] for more data and...[is] more evident' (Charmaz 2006, 140).

The implicit process of perception was established as significant in connecting practitioners' analytic processes to envisionment. One participant's engagement with the model was almost exclusively concerned with perception, and culminated in a graphical representation (Figure 3); this was an example of engagement with the implicit assumptions of the model, and specifically with the portrait of knowing at the beginning and end of a unit of study:

For learner analysis: would create a 3D cube in software (or C++programming). 1 $\mathrm{x}$ point on each axis creating a central point, create a sphere eminating [sic] from this point to demonstrate a learner's size of knowledge. There will be 'spikes' therefore the shape would be a learner 'spider' with different length legs. (Tess, Workshop C)

Figure 3. Graphical representation of a portrait of knowing (Tess, Workshop C)

\section{"Journey"}

'Participants' language' is encouraged within grounded theory research (Wiener, 2007, 301) because it preserves situated meanings. Two examples: learning journey and distance travelled were discounted as categories in their own right because they did not sufficiently account for the nature of practitioners' engagement with the conceptual model. They were however significant, because examples of this participant language were evident across all three categories, and associated with each of the implicit 
processes. In this sense, they also contributed to what carried the theoretical analysis forward. Journey [my aggregated term] was most often associated with symbolised summative analysis. There were also clear examples of practitioners using journey within envisioning analytic processes.

Charmaz $(2006,55)$ suggests problematising participants' 'special terms', and exploring the assumptions that they reflect. Journey contributes to my grounded theory framework because it:

- connects the target/s of my enquiry with their context/s (Plauborg, 2009);

- acts as a bridge between symbolisation and envisionment;

- acts as a bridge to the conceptualisation of a portrait of knowing.

Journey therefore makes a significant contribution to training practitioners developing a greater tolerance for a non-binary conceptualisation of knowing. I cannot argue that it is more evident, or accounts for more data in the sense that a category with 'carrying capacity' (Charmaz 2006, 139) does, but journey has substance. It is emergent and situated. It performs a connective role, contributes to answering the first research question, and completes the substantive grounded theory framework (Figure 4).

Figure 4. How practitioners engage with a model of knowing based on three dimensions of width, depth and materiality: a substantive grounded theory framework.

\section{Evidence of learning taking place}


Coghlan and Pedler's (2006) third criterion for evaluating the quality of action learning research encourages the exploration of personal-, practitioner- and wider-system learning. In my EdD dissertation, I connect the latter two to my second research question, discussion of which is outwith the scope of this article.

Charmaz $(2006,181)$ describes personal learning as 'The sense we make of the journey ... in our completed work'. The substantive constructivist grounded theory framework (Figure 4) helps me understand the reality of my 'experienced problem' (Coghlan and Pedler 2006, 129). My model of knowing, based on three dimensions of generality, complexity and materiality provided a framework which effectively supported training PCET practitioners to reflect on how they think about (their own, and others') knowing. The research illuminated three types of professional analytic behaviour demonstrated when training PCET practitioners were asked to think about knowing: indicative, performative and summative. The properties of these behaviours ranged from expressive symbolisation to explanatory envisionment.

The implications of the research are that my model could support an alternative to a binary epistemology, commonly associated with the PCET curriculum. Used as a conceptual 'tool' within PCET teacher education, Dimensions of knowing has the potential to lighten a dualist 'experiential residue' (Tomlinson 1999, 535).

This small scale study should be considered a starting point, rather than a finish, and three recommendations for further research are made:

- A larger study would offer the opportunity to develop a formal grounded theory, aimed at fuzzy generalisations and wider-setting relatability (Bassey 1999). 
- A study focussed on the participant-language of learning journey would enable the significance of this situated meaning (Wiener 2007; Charmaz 2006) to be better understood.

- A study geared towards challenging PCET trainee teachers' 'experiential residue' (Tomlinson 1999, 535) would determine the extent to which alternative conceptualisations of knowing could be effectively embedded in the postcompulsory curriculum.

\section{End note}

The Further Education Teachers' Qualifications (England) Regulations 2007 were revoked by the coalition government in September 2013, leaving individual employers with responsibility for deciding which qualifications their staff must hold, or work towards. The Education and Training Foundation was formed in 2014 with responsibility for ' ...raising standards in teaching, leadership and workforce development within the [renamed] education and training sector' (et-foundation, 2014a). They have developed 'New Professional Standards' for teachers and trainers, designed to support practitioners to be '...reflective and enquiring...[to] think critically about their own educational assumptions, values and practice in the context of a changing contemporary and educational world' (etfoundation, 2014b). A suite of teaching qualifications remains, ranging from Qualifications and Credit Framework (QCF) Level 3 - 5 and many Higher Education Institutions continue to offer qualifications embedded within Level $5-7$ programmes. 


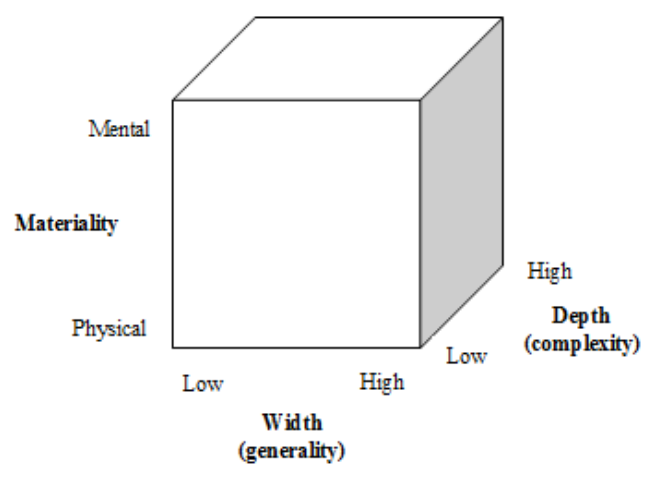

Figure.1.Dimensions of knowing \#1 (Rand 2009, 22)

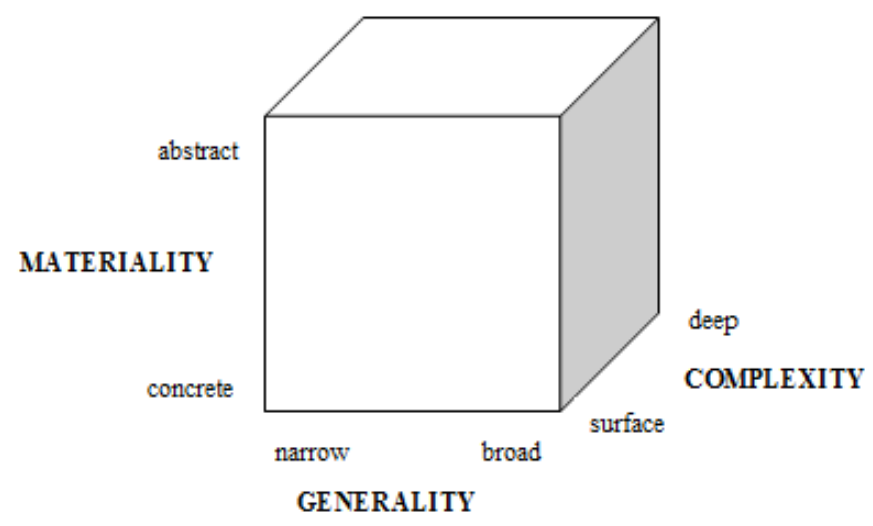

Figure. 2. Dimensions of knowing \#3 (Rand, 2011) 

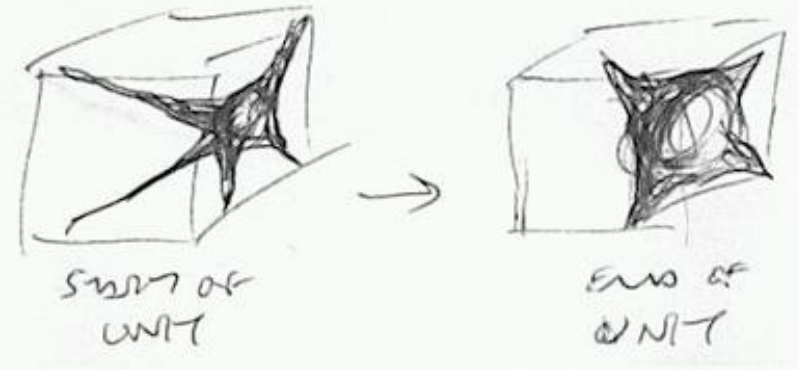

Figure 3. Graphical representation of a portrait of knowing (Tess, Workshop C)

\begin{tabular}{|l|l|l|l|}
\hline \multirow{2}{*}{$\begin{array}{l}\text { Analysis geared } \\
\text { towards.... }\end{array}$} & $\begin{array}{l}\text { Implicit professional } \\
\text { questions }\end{array}$ & \multicolumn{2}{|c|}{ Language (of the research) } \\
\cline { 3 - 4 } & $\begin{array}{l}\text { (Grounded } \\
\text { theory) category }\end{array}$ & Lay term \\
\hline $\begin{array}{l}\text { Identification of a state } \\
\text { or condition }\end{array}$ & $\begin{array}{l}\text { Where (now)? } \\
\text { Why this } \\
\text { state/condition? }\end{array}$ & Indicative analysis & "understanding" \\
\hline Bringing about action & $\begin{array}{l}\text { Where to? } \\
\text { How? }\end{array}$ & $\begin{array}{l}\text { Performative } \\
\text { analysis }\end{array}$ & "doing" \\
\hline $\begin{array}{l}\text { Coming to a final } \\
\text { judgement }\end{array}$ & $\begin{array}{l}\text { What? } \\
\text { How much? } \\
\text { What now? }\end{array}$ & $\begin{array}{l}\text { Summative } \\
\text { analysis }\end{array}$ & "concluding" \\
\hline
\end{tabular}

Table 1. Developing a language for my research 


\begin{tabular}{|c|c|c|}
\hline Analysis type & Implicit question/s & Example \\
\hline Indicative & $\begin{array}{l}\text { Where now? } \\
\text { Why this } \\
\text { condition/state? }\end{array}$ & $\begin{array}{l}\text { Measuring individuals against the three sets of } \\
\text { dimensions would be useful to gauge where they } \\
\text { are now.... Example: someone with deep academic } \\
\text { skills wants to develop a practical skill, represented } \\
\text { by a blob predominantly in the bottom right hand } \\
\text { area of the cube. I(B) } 38 \\
\text { The Dimensions of knowing' is really good for } \\
\text { helping me to decipher any problems with } \\
\text { particular students. For example if a student has } \\
\text { width of knowledge but no depth [it] could lead to } \\
\text { imsecurities for the learner which can lead to } \\
\text { disruption. I(A)18 }\end{array}$ \\
\hline Performative & Where to? How? & $\begin{array}{l}\text { Planning a session or scheme of work. Looking at } \\
\text { the depth and breadth I need to include and } \\
\text { whether the group are more theoretical or practical. } \\
\text { P(B)48 } \\
\text { I will use the key skills builder booklets as already } \\
\text { intended. However, rather than have my learners } \\
\text { simply wade through the books, I will use the book } \\
\text { themes in the workshop to develop physical } \\
\text { knowledge that can be related to mental skills. } \\
\text { Such as the sequencing of pipe lengths. P(A)1 }\end{array}$ \\
\hline Summative & $\begin{array}{l}\text { What? } \\
\text { How much? } \\
\text { What now? }\end{array}$ & $\begin{array}{l}\text { Looking at where I started and where I am now } \\
\text { and how to understand how much I have achieved } \\
\text { and what I really knew before, and now. S(A)4 } \\
\text { The model could be used to measure the distance } \\
\text { travelled by a learner... This would show how } \\
\text { their knowledge had increased and highlight areas } \\
\text { it had improved more in than others. S(B)7 }\end{array}$ \\
\hline
\end{tabular}

Table 2. Examples of the three analytic processes, 


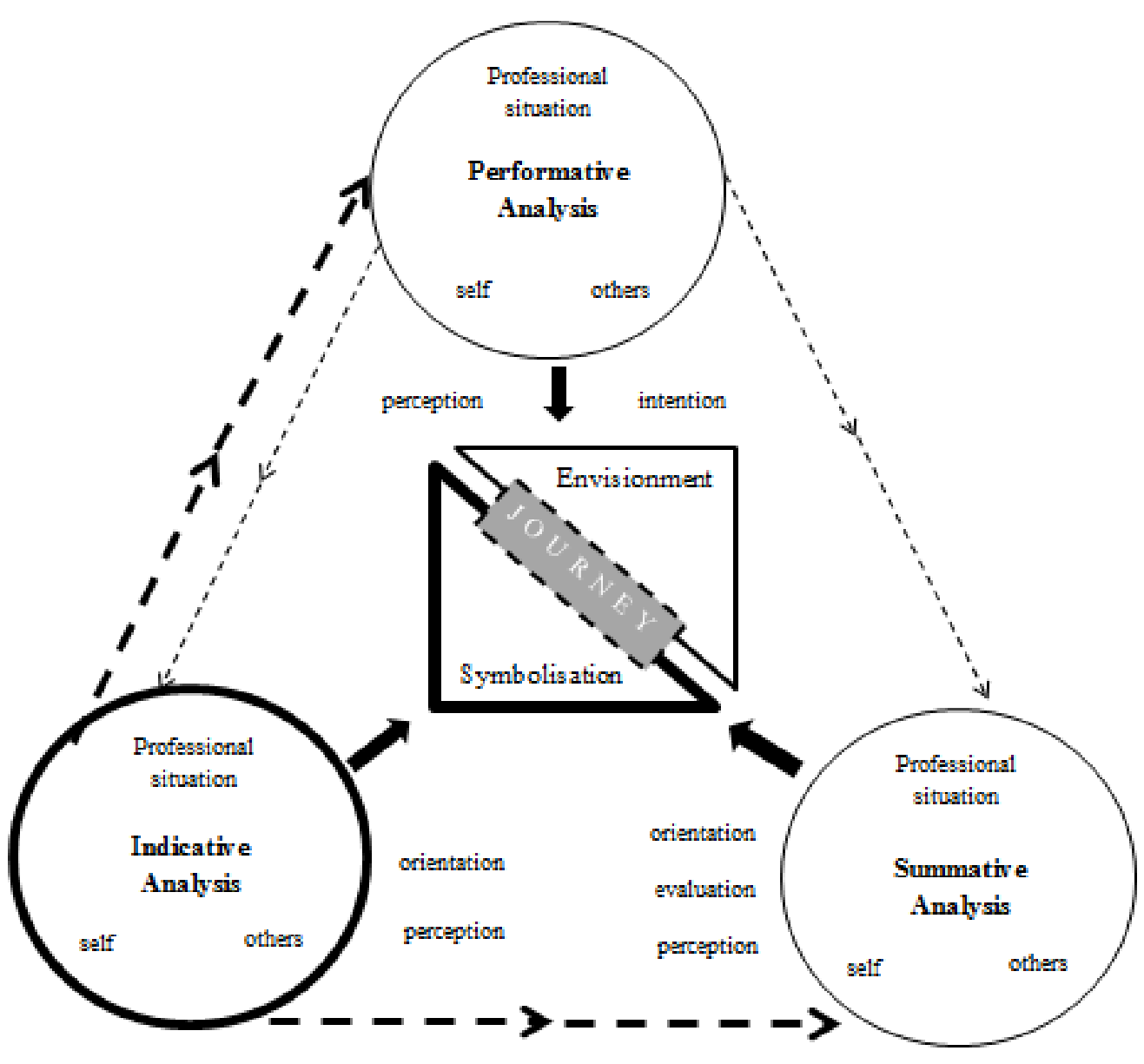

Fisure 4. How practitioners engage with a model of knowing based on three dimensions of width, depth and materiality: a substantive grounded theory framework. 
References

Ainley, P. 2000. "Teaching in a Learning Society, the Acquisition of Professional Skills". Paper presented at the ESRC Teaching and Learning First Programme Conference, Leicester, November. http://www.tlrp.org/acadpub/Ainley2000.pdf

Albino, V., A.C. Garavelli, and G. Schiuma. 2001. "A metric for measuring knowledge codification in organisation learning." Technovation 21: 413-422.

Ancori, B., A. Bureth, and P. Cohendet. 2000. "The Economics of Knowledge: The Debate about Codification and Tacit Knowledge." Industrial and Corporate Change 9 (2): 255-287.

Bassey, M. 1999. Case Study Research in Educational Settings. Maidenhead: Open University Press.

Bathmaker, A. 1999. "Managing Messes and Coping with Uncertainty: reviewing training for teachers in post-compulsory education and training." Journal of Further and Higher Education 23 (2): 185-195.

BERA (British Educational Research Association) 2004. "Revised Ethical Guidelines for Educational Research". http://www.bera.ac.uk/publications/pdfs/ETHICA1.PDF

Bourner, T., and P. Simpson. 2005. "Practitioner-centred research and the Ph.D." Action Learning: Research and Practice 2 (2): 133-151.

Bowen, G.A. 2006. “Grounded Theory and Sensitizing Concepts.” International Journal of Qualitative Methods 5 (3): 1-9.

Charmaz, K. 2006. Constructing Grounded Theory A Practical Guide Through Qualitative Analysis. London: Sage.

Claxton, G. 2006. "Expanding the capacity to learn: A new end for education?" Keynote Address at the British Educational Research Association Annual Conference, Warwick University, September. http://www.guyclaxton.com/documents/New/BERA\%20Keynote\%20Final.pdf

Coghlan, D. and M. Pedler. 2006. "Action learning dissertations: structure, supervision and examination." Action Learning Research and Practice 3 (2): 127-139.

Dehmel, A. 2006. "Teacher education for the vocational education and training sector in England and Germany: Similar challenges, but different approaches?" Paper presented at the Institute of Education Conference, London, May. http://www.ioe.ac.uk/May2006/Papers/AlexandraDehmel_Paper.doc 
DfES (Department for Education and Skills) 2004. Equipping our Teachers for the Future: Reforming Initial Teacher Training for the Learning and Skills Sector. London: DfES.

Entwistle, N. 1995. "Frameworks for Understanding as Experienced in Essay Writing and in Preparing for Examinations." Educational Psychologist 30 (1): 47-54.

Entwistle, N. 2000. "Promoting deep learning through teaching and assessment: conceptual frameworks and educational contexts." Paper presented at the TLRP Conference, Leicester, November.

Entwistle, N. 2004. "Learning Outcomes and Ways of Thinking across Contrasting Disciplines and Settings in Higher Education." http://www.etl.tla.ed.ac.uk/publications.html

Entwistle, N. 2009. Teaching for Understanding at University. Deep approaches and distinctive ways of thinking. Basingstoke: Palgrave Macmillan.

Entwistle, N., and F. Marton. 1994. "Knowledge objects: understandings constituted through intensive academic study." British Journal of Educational Psychology 64 (1): 161-178.

Entwistle, N., and P. Ramsden. 1983. Understanding Student Learning. London: Croom Helm Ltd.

et-foundation (The Education and Training Foundation) 2014a. "Home". Accessed July 3. http://www.et-foundation.co.uk/

et-foundation (The Education and Training Foundation) 2014b. "Professional Standards for Teachers and Trainers in Education and Training - England" Accessed July 3. http://www.etfoundation.co.uk/supporting/programmes/professional-standards/

Holton, J.A. 2007. “The Coding Process and Its Challenges.” In The SAGE Handbook of Grounded Theory, edited by A. Bryant, and K. Charmaz. 2010. Paperback ed., 265-290. London: Sage.

Illeris, K. 2006. How we learn. Learning and non-learning in school and beyond. 2nd ed. Abingdon: Routledge.

Kolb, D.A. 1984. Experiential Learning - Experience as the source of learning and development. New Jersey: Prentice Hall.

LaRossa, R. 2005. "Grounded Theory Methods and Qualitative Family Research. Journal of Marriage and Family." 67: 837-857. 
Lempert, L.B. 2007. “Asking Questions of the Data: Memo Writing in the Grounded Theory Tradition." In The SAGE Handbook of Grounded Theory, edited by A. Bryant, and K. Charmaz. 2010. Paperback ed., 245-264. London: Sage.

Lord, B. 1994 “Teachers' professional development: Critical colleagueship and the role of professional communities." In The Future of Education: Perspectives on national standards in education, edited by N.Cobb. 175-204. New York: College Board.

Marshall, C., \& Rossman, G.B. (2006). Designing Qualitative Research (4th ed.). London, England: Sage.

Marton, F., and R. Säljö. 2005. “Approaches to Learning.” In The Experience of Learning: Implications for teaching and studying in higher education. $3^{\text {rd }} \mathrm{ed}$., edited by F. Marton., D. Hounsell., and N. Entwistle, 39-58. Edinburgh, Scotland: University of Edinburgh, Centre for Teaching, Learning and Assessment.

Mezirow, J.1981. "A critical theory of adult learning and education." Adult Education 32 (1): 3-24.

McGill, I., and A. Brockbank. 2004. The Action Learning Handbook. Powerful techniques for education, professional development \& training. Abingdon: RoutledgeFalmer.

OECD (The Organisation for Economic Co-operation and Development). 1996. The Knowledge-Based Economy. Paris: OECD.

Moghaddam, A. 2006. "Coding issues in grounded theory." Issues in Educational Research,16. http://www.iier.org.au/iier16/moghaddam.html

Nickerson, R.S. 1985. “Understanding Understanding.” American Journal of Education 93 2: 201-239.

Pedler, M. 2001. "Writing from practice.” Human Resource Development International 4 (3): 295-298.

Plauborg, H. 2009. “Opportunities and limitations for learning within teachers' collaboration in teams: perspectives from action learning." Action Learning: Research and Practice 6 (1): 25-34.

Rand, J. 2009. "Whither knowledge and skills? A call for complementarity in postcompulsory education.” Unpublished EdD coursework, University of Sheffield.

Rand, J. 2011. "Dimensions of knowing: a constructivist exploration of a conceptual model in a real context." EdD diss., University of Sheffield. 
Rand, J. 2013. "Action Learning and constructivist grounded theory: powerfully overlapping fields of practice.” Action Learning: Research and Practice 10 (3): 230-243.

Säljö, R. 1979. “Learning about Learning.” Higher Education 8 (4): 443-451.

The Further Education Teachers' Qualifications (England) Regulations, 2007. SI 2007/2264. London: The Stationery Office.

Tomlinson, P. 1999. “Conscious Reflection and Implicit Learning in Teacher Preparation. Part II: Implications for a balanced approach." Oxford Review of Education 25 (4): 533-544.

van den Hoonaard, W.C. 1997. Working with sensitizing concepts: analytical field research. London: Sage.

Wiener, C. 2007. "Making Teams Work in Conducting Grounded Theory." In The SAGE Handbook of Grounded Theory, edited by A. Bryant, and K. Charmaz. 2010. Paperback ed., 294-310. London: Sage. 